\title{
ZnO/VNC Material for UV-Photodegradation of Methylene Blue
}

\author{
A. Arunkumar, T. Chandrasekaran, K. Riaz Ahamed* \\ PG and Research Department of Chemistry, Jamal Mohamed College (Autonomous), \\ Tiruchirappalli -620 020, Tamil Nadu, India.
}

Corresponding author: email-profriaz@yahoo.co.in

Keywords: Methylene blue (MB), ZnO / VNC, FT-IR, SEM, XRD

\begin{abstract}
ZnO materials act as a Photocatalytic reaction and it leads to partial or complete mineralization or decolorization of organic pollutants. Upon irradiation with $\mathrm{UV} / \mathrm{visible} \mathrm{light,}$ semiconductors catalyze undergoes redox reactions in presence of air $/ \mathrm{O}_{2}$ and water. In the present study Zinc oxide $(\mathrm{ZnO})$ was doped with activated carbon prepared from the stem of the plant material by chemical activation namely, Vitex negundo stem carbon (VNC). The decolourisation and degradation study of a dye namely, methylene blue (MB) was carried out to find out the efficiency of catalytic property of $\mathrm{ZnO} / \mathrm{VNC}$. The reaction was performed at 20, 40,60 ppm solute $\mathrm{ZnO} / \mathrm{VNC}$ ion at $10 \mathrm{~min}$ interval of time. It found that the prepared $\mathrm{ZnO} / \mathrm{VNC}$ composite exhibits an enhanced Photocatalytic activity for MB degradation under visible light irradiation and its photo catalysis efficiency was analyzed in specific $663 \mathrm{~nm} \lambda$ max using a UV-vis-spectrophotometer. The surface morphology and functional group present in the $\mathrm{ZnO} / \mathrm{VNC}$ material was characterized by using FT-IR, SEM and XRD. The result reveals that the $\mathrm{ZnO} / \mathrm{VNC}$ structure consists of irregular aggregates with rough surfaces and high photodegradation activities of $\mathrm{ZnO} / \mathrm{VNC}$ on $\mathrm{MB}$ solutions are found to be at $20 \mathrm{ppm}$. The $\mathrm{ZnO} / \mathrm{VNC}$ may be used as an alternative adsorbent to remove $\mathrm{MB}$ from aqueous solutions.
\end{abstract}

\section{INTRODUCTION}

Wastewater from textile, paper, and some other industries contain residual dyes, which are not readily biodegradable. Adsorption and chemical coagulation are the two common techniques of treatment of such wastewater. However, these methods merely transfer dyes from the liquid to the solid phase causing secondary pollution and requiring further treatment. Wastewaters contaminated with residual dyes from textile, paper and other industries are a source of environmental problems, especially in third world countries [1]. Photocatalytic degradation of organic pollutants in water and air using semi conductive particles, such as $\mathrm{TiO}_{2}$ and $\mathrm{ZnO}$, has attracted extensive attention in the past two decades $[2,3]$.

In particular, $\mathrm{ZnO}$ has attracted much attention with respect to the degradation of various pollutants due to its high photosensitivity, stability and wide band gap. While $\mathrm{TiO}_{2}$ is widely employed as a Photo catalyst, $\mathrm{ZnO}$ is a suitable alternative to $\mathrm{TiO}_{2}$ as it has a similar band gap energy $(3.2 \mathrm{eV})$ [4], larger quantum efficiency than $\mathrm{TiO}_{2}$ and higher photocatalytic efficiencies have been reported Poulios and Tsachpinis $[5,6,7,8]$. Semiconductors (such as $\mathrm{TiO}_{2}, \mathrm{ZnO}, \mathrm{Fe}_{2} \mathrm{O}_{3}, \mathrm{CdS}$, and $\mathrm{ZnS}$ ) can act as sensitizers for light-induced redox-processes due to the electronic structure of the metal atoms in chemical combination, which is characterized by a filled valence band, and an empty conduction band [9]. The quantum efficiency of $\mathrm{ZnO}$ powder is also significantly larger than that of $\mathrm{TiO}_{2}$ powder, and higher catalytic efficiencies have been reported for $\mathrm{ZnO}$ [10]. Using $\mathrm{ZnO}$ irradiated with sunlight. Here also the photodegradation efficiency decreased with an increase in initial dye concentration. Optimum catalyst loading was found to be $250 \mathrm{mg}$ in $100 \mathrm{ml}$. These are the major variables governing the efficiency of the process because the former does not always confirm the latter. The initial rates of reaction were calculated for various initial dye concentrations. Therefore, it is an important way to promote the photo catalysis efficiency by decreasing the recombination rate. $\mathrm{ZnO}$ with higher Photo catalytic efficiency than $\mathrm{TiO}_{2}$ holds the drawback of photo corrosion effect during light irradiation and causes the decrease in Photocatalytic activity and stability [11]. Conventional treatment of such wastewater generally involves coagulation/ 
flocculation [12, 13] electro-coagulation [14], coagulation/carbon adsorption process [15] and so on. These methods, however, merely transfer dyes from the liquid-phase to the solid-phase, requiring further treatment and causing secondary pollution. In the past two decades, photo catalysis by semi conductive materials such as $\mathrm{TiO}_{2}$ and $\mathrm{ZnO}$ has attracted public concern as a promising tool among the advanced oxidation processes to substitute the traditional wastewater treatment due to their high photosensitivity, non-toxic nature, high stability, and wide band gap.

Activated carbon available commercially and it also been prepared from available natural source like biodegradable material. Activation process is an important process for preparing activated carbon. Processing by chemical activation involves of the raw material with dehydrating chemical agents including phosphoric acid, sulfuric acid, potassium hydroxide and zinc chloride. The main focus of the present work is to use commercially available $\mathrm{ZnO}$ in the Photo catalytic decolourisation and degradation study of methylene blue (MB) it is suggested that the Photocatalytic method can be effectively applied to decolourise and degrade the effluent if repeated in multiple steps. The aim of the present work is to investigate the potential of $\mathrm{ZnO} / \mathrm{VNC}$ as a Photo catalyst under UV radiation for the oxidation of Methylene Blue in aqueous solutions.

\section{EXPERIMENTAL METHODS}

\subsection{Materials}

All chemicals used in the experiments were of analytical grade obtained from Merck, Mumbai, India. $\mathrm{ZnSO}_{4}\left(99.98 \%\right.$ \%), $\mathrm{NH}_{4} \mathrm{HCO}_{3}$ (99.99), Methylene Blue (MB), $\mathrm{H}_{2} \mathrm{SO}_{4}, \mathrm{NaOH}$ and Methylene Blue: Chemical formula $=\mathrm{C}_{16} \mathrm{H}_{18} \mathrm{~N}_{3} \mathrm{SCl}, \mathrm{MW}=319.85222 \mathrm{~g} / \mathrm{mol}, \lambda$ max $665 \mathrm{~nm}$, was supplied by Merck. The required experimental solutions of the desired concentration were prepared by diluting the stock solution with distilled water.

\subsection{Preparation of VNC Carbon}

The activated carbon prepared from stem of the plant vitex negundo stem by chemical activation. Due to the presence of acidic nature, dehydrating and oxidizing property $\mathrm{H}_{2} \mathrm{SO}_{4}$ is used as an activating agent. By using chemical activation, the increase of porous structure of activated carbon can be prepared by activation in absence of air at $600^{\circ} \mathrm{c}$ using muffle furnace. The carbon obtained was washed with Double distilled water for several times until the activating agent present on the surface of activated carbon has been removed completely. The final carbon powder was sieved and stored in airtight container. In order to analyze the prepared activated carbon, several standard analyses were employed to characterize the activated carbon such as the pore size analysis, surface functional groups analysis and it has been reported in previous studies [16].

\subsection{Preparation of $\mathrm{ZnO}$}

The preparation of $\mathrm{ZnO}$ obtained [17] $1 \mathrm{~g}$ of VNC activated carbon and $50 \mathrm{ml}$ of $1.0 \mathrm{M}$ $\mathrm{ZnSO}_{4}$ solution was added drop wise into $60 \mathrm{ml}$ of $2.0 \mathrm{M} \mathrm{NH}_{4} \mathrm{HCO}_{3}$ solution under vigorous stirring at $60^{\circ} \mathrm{C}$ in a water bath for $1 \mathrm{~h}$. The as-synthesized white precipitate was isolated by filtration, washed for three times with distilled water and ethanol, and then dried in a vacuum oven at $60^{\circ} \mathrm{C}$ for $24 \mathrm{~h}$. Finally, the product was calcinations at $600^{\circ} \mathrm{C}$ for $1 \mathrm{~h}$ to obtain white powder of $\mathrm{ZnO}$

\subsection{Photo catalytic Measurements}

The Photocatalytic performance of the as-prepared samples was evaluated by Photocatalytic degradation of methylene blue under UV light irradiation. The samples $(0.1 \mathrm{~g})$ were dispersed in $100 \mathrm{ml}$ solutions $(10 \mathrm{mg} / \mathrm{l})$ which were prepared by into deionised water. The mixed suspensions were first magnetically stirred in the dark for $30 \mathrm{~min}$ to reach the adsorption-desorption equilibrium. Under stirring, the mixed suspensions were exposed to UV irradiation produced by alternative sunlight. At certain time intervals, $5 \mathrm{ml}$ of the mixed suspensions were extracted and centrifugated to remove the photo catalyst. The filtrates were analyzed by recording UV-vis spectra of methylene blue using a jasco-650, UV-vis spectrophotometer Therefore, the photo-stability of as-prepared sample was evaluated for methylene blue under UV light irradiation. 


\subsection{Characterization}

The preparation of activated carbon and doped with $\mathrm{ZnO}$ by characterization surface morphology structure, High resolution scanning electron microscope (HR-SEM) F E I Quanta FEG200 ZEISS. The X-ray powder diffraction (XRD) measurements were carried out using X'Pertpropan analytical Diffracstometer using $\mathrm{Cu} \mathrm{K} \alpha$ radiation as the X-Ray source. FT-IR spectra of the samples were recorded in the range of $400-4000 \mathrm{~cm}^{1}$ shimadzu spectrometer. The photo catalytic degradation methylene blue sample analysis using a UV-Visible spectroscopy modal (jasco-50)

\section{RESULT AND DISCUSSIONS}

\subsection{Scanning Electron Microscope (SEM)}

The morphology and particle sizes were observed by a scanning electron microscope. The morphology and active surface of $\mathrm{ZnO} / \mathrm{VNC}$ materials were briefly explained using Scanning electron microscope and it is shown in Fig. (1a) at different magnifications for VNC material. In VNC carbon the surface found to be smooth porous morphology with pores of different sizes and shapes which conforms that the material posses high surface area to adsorb an impurities from the aqueous solution. The Fig. (1b) doping $\mathrm{ZnO}$ the surface of the carbon material, possess to be sphere like shape, which seems to strong binding of zinc oxide in VNC.

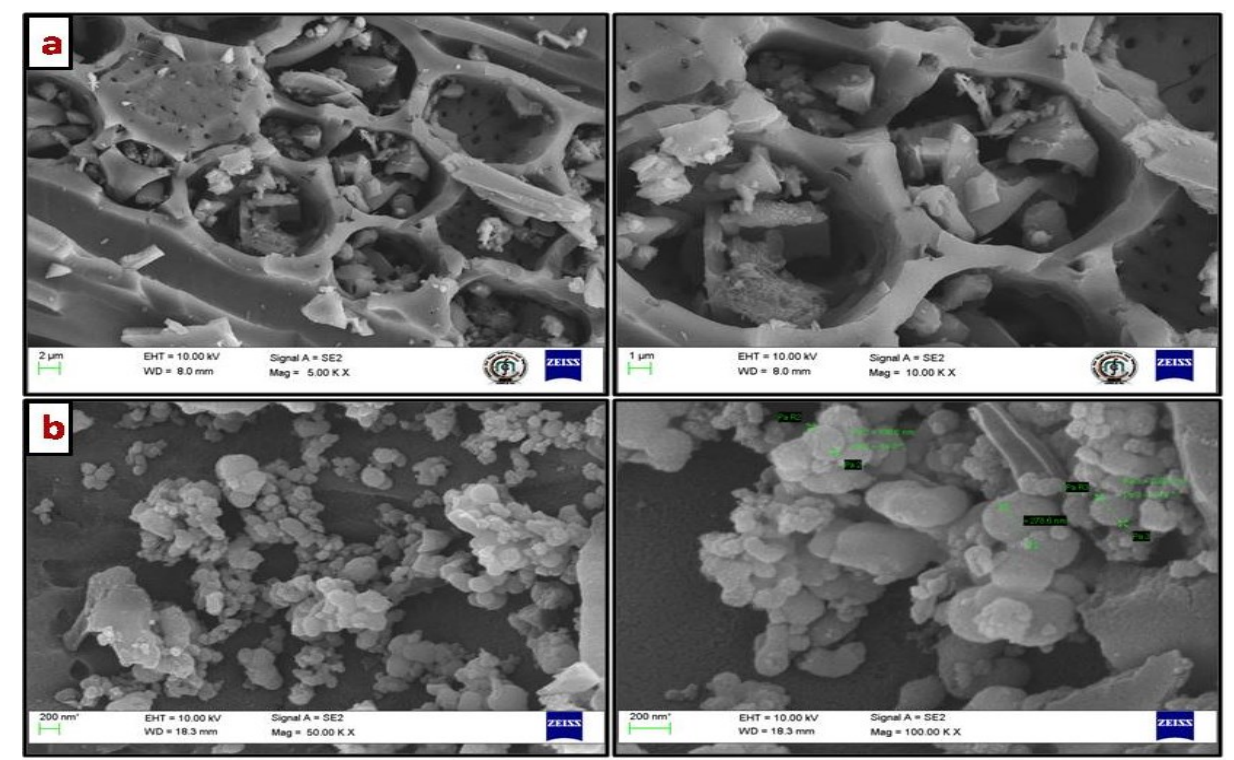

Fig. 1: The SEM image of the (a) VNC Activated carbon (b) $\mathrm{ZnO} / \mathrm{VNC}$

\subsection{X-Ray Diffraction (XRD)}

The $\mathrm{ZnO} / \mathrm{VNC}$ nanocomposites samples exhibit analogous XRD diffraction peaks in terms of $\mathrm{ZnO}$ framework. The dominant peaks located at 31.7, 34.4, 36.3, 47.6, 56.6, 62.9, 66.4, 68.0, 69.1, 72.6, and 77.0 ${ }^{\circ}$ are indexed to (100), (002), (101), (102), (110), (103), (200), (112), (201), (004), and (202) crystallographic planes of hexagonal $\mathrm{ZnO}[18]$. Notably, no diffraction peaks for $\mathrm{VNC}$ (Fig.2,) can be observed in the nanocomposites of $\mathrm{ZnO} / \mathrm{VNC}$. One possible reason might be due to the low amount and relatively low diffraction intensity of VNC in comparison with the diffraction intensity of $\mathrm{ZnO}$. The other is probably due to the disappearance of the layer-stacking regularity after reduction of $\mathrm{VNC}$, indicating that the coupling of $\mathrm{ZnO}$ with $\mathrm{VNC}$ can prevent the restacking of the VNC effectively. 


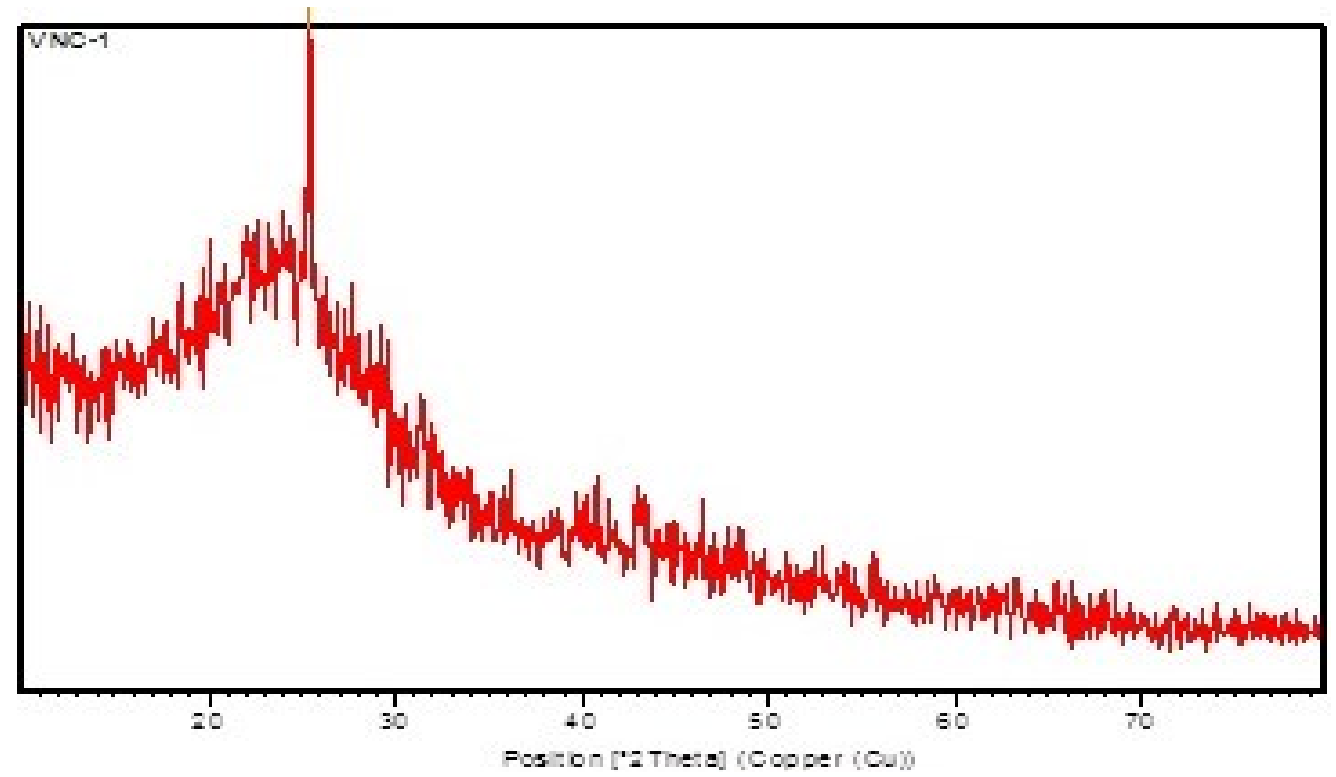

(a)

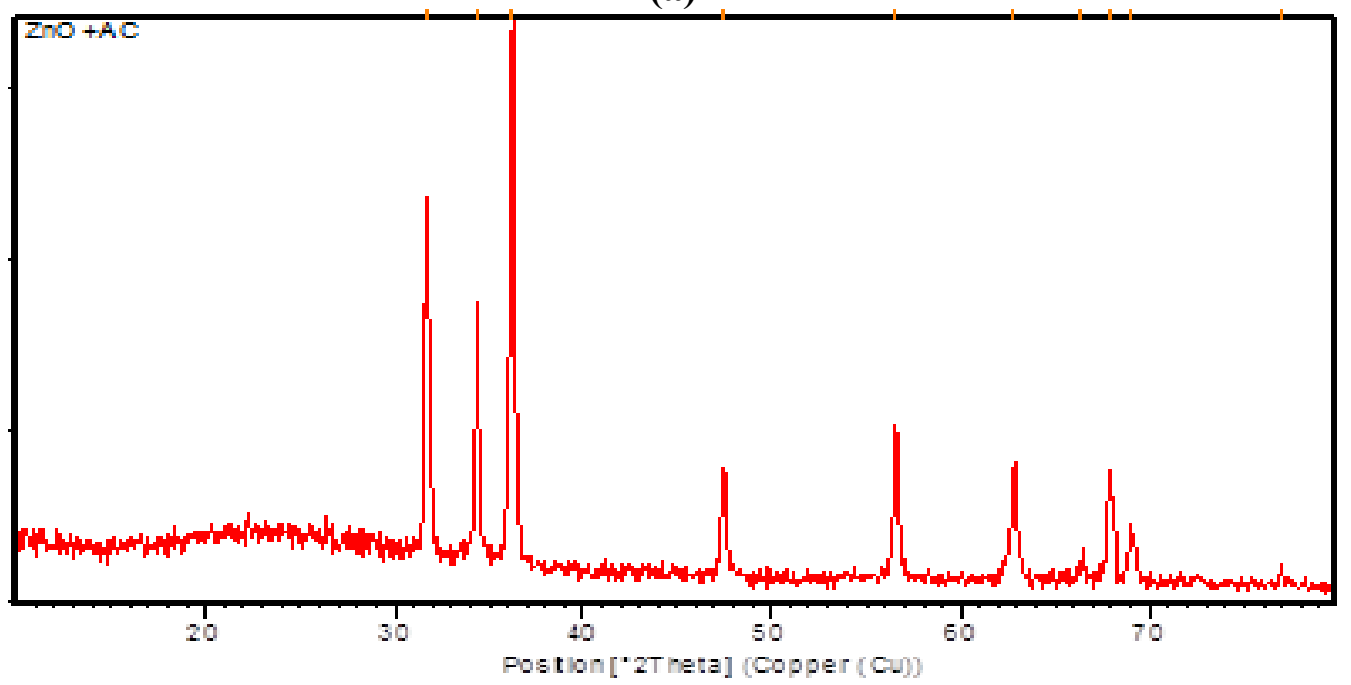

(b)

Fig. 2: XRD pattern of (a) VNC (b) ZnO/VNC

\subsection{FT-IR Spectroscopy}

The IR spectra of the activated carbon and VNC were measured in shimadzu FTIR spectrophotometer [16]. In $\mathrm{ZnO} / \mathrm{VNC}$ the characteristic peaks at $3425.58 \mathrm{~cm}^{-1}$ corresponding to the $\mathrm{OH}$-stretching vibration free hydroxyl group and H-bonded group. A band at $2953.102 \mathrm{~cm}^{-1}$ and $2922.16 \mathrm{~cm}^{-1}$ assigned to $\mathrm{C}-\mathrm{H}$ stretch. The bands at $1683.86 \mathrm{~cm}^{-1}$ were assigned to presence of $\mathrm{C}=\mathrm{O}$ group. The peaks at $675.09 \mathrm{~cm}^{-1}$ show the presence of zinc oxide and hence, the presence of these functional groups helps to adsorb a dye from a test solution. 


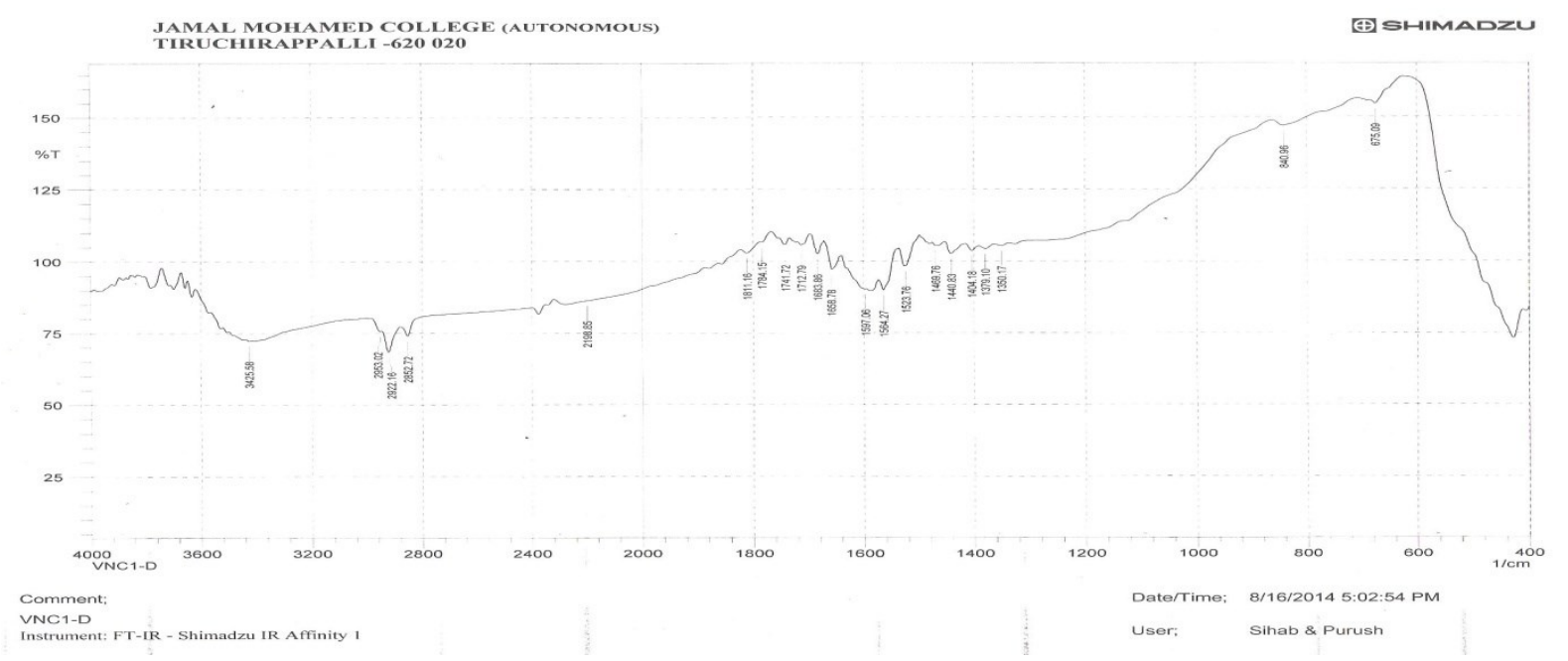

Fig. 3: FT-IR spectrum of $\mathrm{ZnO} / \mathrm{VNC}$ carbon

\subsection{Photodegradation reaction}

The present photodegradation process assisted by a $\mathrm{ZnO}$ was studied by varying the rate determining parameters like concentration of the dye Methylene Blue (MB). Since, the photoassisted degradation of the dyes occurs predominantly on the Photo catalyst surface; studies on the adsorption of the dyes from aqueous solution onto $\mathrm{ZnO}$ particles are relevant and important. The equilibrium concentration of the dye $(\mathrm{Ceq})$ in contact with the catalyst, instead of that of the feed dye solution, represents the true dye-concentration in solution at the start of irradiation [19].

The Fig. 4 shows the UV- visible absorbance spectrum for photodegradation of MB using $\mathrm{ZnO} / \mathrm{VNC}$. The absorption of photon leads to the promotion of electron from the valance band to the conduction band. Thus, the increase in time of irradiation possesses sufficient intensity for photodegradation process. The Photocatalytic activity of the samples was evaluated with respect to the Photocatalytic degradation of $\mathrm{MB}$ with different concentration and $\mathrm{ZnO} / \mathrm{VNC}$ as catalyst were carried out under the presence to investigate the universality of degradation, The Fig.4, It can be observed that the characteristic absorption. In different ppm Photo degradation reaction, at 20ppm, 40ppm, 60ppm shown in the Fig.4. The formation of $\mathrm{ZnO}$ results from the photochemical reaction of $\mathrm{H}_{2} \mathrm{O}_{2}$ and $\mathrm{Zn}\left(\mathrm{CH}_{3} \mathrm{COO}_{2}\right)_{2}$ and the corresponding process is considered as following:

$$
\mathrm{Zn}\left(\mathrm{CH}_{3} \mathrm{COO}_{2}\right)_{2}+\mathrm{H}_{2} \mathrm{O}_{2} \longrightarrow \mathrm{ZnO}_{2}+2 \mathrm{HCH}_{3} \mathrm{COO}_{2}
$$

The $\mathrm{ZnO}_{2}$ decomposes into $\mathrm{ZnO}$ when the sintering temperature is above $200^{\circ} \mathrm{c}$, which agrees well with the theoretical decomposition temperature of zinc peroxide (at about $182.2^{0}$ ) [20]. The decomposition $\mathrm{ZnO}_{2}$ is believed to be:

$$
2 \mathrm{ZnO}_{2} \rightarrow 2 \mathrm{ZnO}+\mathrm{O}_{2}
$$

It is clear from Eq.2, that the by-product in this preparation process is $\mathrm{O}_{2}$, thus it causes no environmental pollution. Already using this plant activated carbon doped with $\mathrm{ZnO} / \mathrm{VNC}$ briefly explains by photo catalytic degradation of methylene blue and malachite green comparative on previous work [21]. 

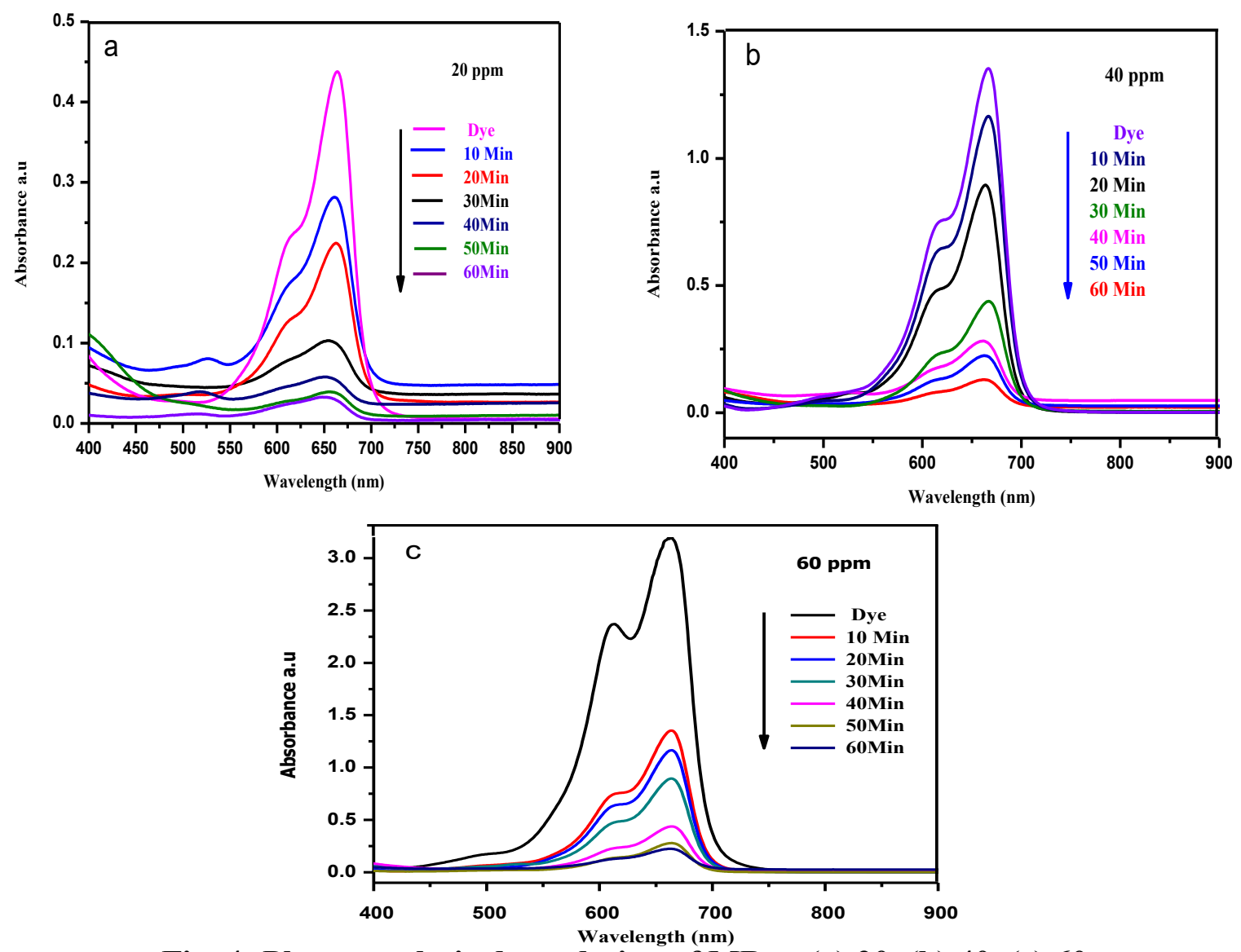

Fig. 4: Photo catalytic degradation of MB at (a) 20, (b) 40, (c) 60 ppm

\section{CONCLUSION}

Photodegradation of methylene dye was studied as a model system using powder $\mathrm{ZnO} / \mathrm{VNC}$ material. From the result of this study, it is concludes that Photocatalytic activity of $\mathrm{ZnO} / \mathrm{VNC}$ can be enhanced by its suitable modification of the absorbing surface. The characteristic evidence of HR-SEM and XRD show that $\mathrm{ZnO}$ randomly anchored onto the carbon materials. The active functional group used for up taking MB from the test solution present in the $\mathrm{VNC}$ and $\mathrm{ZnO} / \mathrm{VNC}$ indentified by using FTIR spectroscopy. The obtained results show that MB easily decolorized by $\mathrm{ZnO} / \mathrm{VNC}$ in aqueous solution under solar light. As a result, the prepared $\mathrm{ZnO} / \mathrm{VNC}$ prove an excellent photo catalytic activity for degradation of $\mathrm{MB}(92 \%)$ under solar light. Due to its effectiveness, high stability, high activity, and reducing power for degradation of environmental pollutants in solar light absorption capability the catalyst used as a photo degradation of pollutant applications in a number of environmental issues. The effluent suggests that the dye molecules could be completely mineralized with the help of $\mathrm{ZnO}$ which is both economically viable and environment friendly.

\section{ACKNOWLEDGEMENT}

The Author would like to acknowledge and extend his heartfelt gratitude to the persons who helped for this research work and thankful to the Principal and Department of Chemistry, Jamal Mohamed College for providing laboratory facilities to perform the experiments. 


\section{REFERENCES}

[1] R.W. Matthews, Controlled Synthesis of $\mathrm{TiO} 2$ Hierarchical Nanofibre Structures via Electrospinning and Solvothermal Processes: Photocatalytic Activity for Degradation of Methylene Blue.Water Res. 25 (1991) 1169-1176.

[2] A. Sharma, P. Rao, R.P. Mathur, S.C. Ameta, Photocatalytic reactions of xylidin ponceau on Semiconducting zinc oxide powder J. Photochem. Photobiol. A: Chem. 86 (1995) 197-200.

[3] S. Sakthivel, B. Neppolian,M.V. Shankar, B. Arabindoo, M. Palanichamy,V. Murugesan, Solar photocatalytic degradation of azo dye: comparison of photocatalytic efficiency of $\mathrm{ZnO}$ And TiO2, Sol. Energy Mater. Sol. Cells .77 (2003) 65-82.

[4] A.A. Khodja, T. Sehili, J.F. Pilichowski,P.Boule,"Photocatalyticdegradationof2phenylphenol On TiO2 and ZnO in aqueous suspensions,"J. Photochem. Photobiol.A: Chem. 141(2001) 231-239.

[5] I. Poulios, I. Tsachpinis, Photodegradation of the textile dye Reactive Black 5 in the presence of semiconducting oxides. J. Chem. Technol. Biotechnol. 74 (1999) 349-357.

[6] M.R. Hoffmann, S.T. Martin, W. Choi, D.W. Bahenemann, Environmental applications of Semiconductor photocatalysisChem.Rev 95 (1995) 69-96.

[7] S. Sakthivel, B. Neppolian, M. Palanichamy, B. Arabindoo, V. Murugesan, Indian Photocatalytic degradation of leather dye, Acid green 16 using $\mathrm{ZnO}$ in the slurry and thin Filmforms J.Chem. Technol. 6 (1999) 161-165.

[8] Ye, C.; Bando, Y.; Shen, G.; Golberg, D. Thickness dependent photocatalytic Performance of ZnO nano platelets. J. Phys. Chem.B, 110 (2006) 15146-15151.

[9] C. Allegre, M. Maisseu, F. Charbit, P. Moulin,Coagulation-flocculation-decantation of dye House effluents: concentrated effluents, J. Hazard. Mater. B 116 (2004) 57-64.

[10] V. Golob, A. Vinder, M. Simonic, Efficiency of the coagulation/flocculation method for the Treatment of dye bath effluents, Dyes Pigments 67 (2005) 93-97.

[11] A.Alinsafi, M.Khemis, M.N.Pons, J.P.Leclerc, A.Yacoubi, A.Benhammou, A.Nejmeddine, Elect Ro-coagulation of reactive textile dyes and textile wastewater, Chem. Eng. Proc. 44 (2005) 461-470.

[12] S. Papic, N. Koprivanac, A. LoncaricBozic, A. Metes, Removal of some reactive dyes from Synthetic wastewater by combined Al (III) coagulation/carbon adsorption process, Dyes Pigments 62 (2004) 291-298.

[13] K. Tanaka, K. Padermpole, T.Hisanaga, Photocatalytic degradation of commercial azo dyes, Water Res. 34 (2000) 327-333.

[14] N.S.Allen, M. Edge, J. Verran, J. Stratton, J. Maltby, C. Bygott, Photocatalytictitania based Surfaces: environmental benefits, Polym. Degrad. Stab. 9 (2008)

[15] F. Zhang, J. Zhao, T. Shen, H. Hidaka,E.Pelizzetti,N.Serpone,TiO2assistedphotodegradation of dye pollutants II. Adsorption and degradation kinetics of eosin in TiO 2 dispersion under Visible light irradiation Appl. Catal. B Environ.15 (1998) 147-156.

[16] A.Arunkumar, T.Chandrasekaran, K. Riaz Ahamed, 'Preparation of Activated Carbon from The Stem of the Natural Plant Vitex Negundo and Evaluation of Their Physical and Chemical Properties'. Int. J. Innov. Technol. Explor. Eng .4(2) (2014) 1-6.

[17] G.C.C. Yang, S.W. Chan, Photocatalytic reduction of chromium (VI) in aqueous solution using dye-sensitized nanoscale $\mathrm{ZnO}$ under visible light irradiation, J. Nanopart. Res. 11 (2009) 221-230.

[18] B. D. Cullity, Elements of X-ray Diffractions, Addison-Wesley, MA, 1978

[19] A. Sharma, P. Rao, R.P. Mathur, S.C. Ameta, Photo catalytic reactions of xylidineponceau on semiconducting zinc oxide powder, J.Photochem. Photobiol. A: Chem. 86 (1995) 197-200.

[20] D.Wang; C.Song, Controllable synthesis of $\mathrm{ZnO}$ nanorod andprism arrays in a large area. J. Phys. Chem. B, 109 (2005) 12697-12700.

[21] A.Arunkumar, T. Chandrasekaran, K. Riaz ahamed, ' $\mathrm{ZnO}$ doped with activated carbon for Photocatalytic degradation of Methylene Blue and Malachite Green on UV-visible Light' Int. J. Nano. Corr. Sci. and Engg, 2(5) (2015) 300-307 . 